\title{
OPTIMALISASI DOSIS KOAGULAN DAN PENINGKATAN KINERJA PAC (POLY ALUMINIUM KLORIDA) DENGAN PENAMBAHAN KAUSTIK SODA DALAM PROSES PENGOLAHAN AIR BERSIH DI PDAM BANDARMASIH KOTA BANJARMASIN MENGGUNAKAN METODE JAR TEST
}

\author{
Alfian Nor ${ }^{1}$, Idzani Muttaqin ${ }^{1}$, Ice Trianiza ${ }^{1}$ \\ Program Studi Teknik Industri, Fakultas Teknik \\ Universitas Islam Kalimantan Muhammad Arsyad Al Banjari Banjarmasin \\ Jl. Adhyaksa No.2 Kayutangi Banjarmasin \\ e-mail: alfiannor195@gmail.com
}

\begin{abstract}
Abstrak- Proses penambahan koagulan harus dilakukan secara efisien karena proses koagulasi ini merupakan proses yang menghabiskan biaya terbesar dari serangkaian proses pengolahan air yang ada di PDAM Bandarmasih. Jika dosis penambahan koagulan dilakukan secara berlebihan, akan menyebabkan biaya penggunaan bahan kimia koagulan menjadi membengkak sehingga membebani pengeluaran PDAM. Metode dalam penelitian ini yang akan digunakan yaitu dengan metode analitik dimana data dari hasil uji coba beberapa dosis koagulan Poli Aluminium Klorida (PAC) yang digunakan pada kegiatan jar test diteliti untuk dijadikan dasar dalam menentukan jumlah atau dosis koagulan Poli Aluminium Klorida (PAC) yang paling optimal. Hasil penelitian sebagai berikut :Dosis optimum koagulan PAC (Poly Aluminium Klorida) untuk pengolahan air bersih di PDAM Bandarmasih sebesar 48 mg/l dengan paramater kekeruhan hasil jar test sebesar 1,44 NTU untuk metode jar test 1 dan 0,88 NTU untuk metode jar test 2.Penambahan kaustik soda / soda ash berpengaruh terhadap peningkatan hasil uji jar test untuk tingkat kekeruhan dan efisiensi pengolahan. Dimana dengan menambahkan kaustik soda / soda ash, nilai parameter kekeruhan menjadi lebih kecil $(0,88$ NTU) dan nilai efisiensi pengolahan menjadi lebih besar (95\%). Peningkatan hasil uji jar test disebabkan karena adanya peningkatan $\mathrm{pH}$ air yang akan di olah menjadi 7,3 dimana kondisi pH air tesebut masuk kedalam kondisi pH optimal kinerja koagulan PAC (Poly Aluminium Klorida) yang berada di kisaran pH 7,1 sampai dengan 7,5.
\end{abstract}

Kata Kunci-Peningkatan Kinerja, Metode Jar Test

\section{PENDAHULUAN}

$\mathrm{S}$ ebagai salah satu sumber penyangga kehidupan, air memegang peranan vital di setiap sendi kehidupan manusia. Didalam kehidupan, air memiliki berbagai fungsi antara lain: mengatur suhu tubuh, sumber mineral alami, pembentuk cairan darah, dan berperan penting dalam berbagai proses pencernaan. Sumber air di bumi dapat diperoleh dari berbagai sumber seperti sungai, danau, waduk, dan mata air. Tiap sumber air, memiliki kualitas air yang berbeda-beda dari segi fisik, warna maupun kandungan kimia didalamnya.

Dari tiap sumber air tersebut, sungai merupakan salah satu sumber air permukaan yang sering dimanfaatkan oleh manusia dalam memenuhi kebutuhan hidupnya sehari hari. Begitu pula untuk wilayah banjarmasin, sungai merupakan sumber air baku yang digunakan oleh PDAM Bandarmasih dalam memproduksi air bersih yang akan di distribusikan keseluruh masyarakat Banjarmasin. Akan tetapi, kondisi kualitas air sungai saat ini telah jauh mengalami penurunan terutama dari sisi kekeruhannya. Jika mengacu kepada standar kekeruhan yang ada, air sungai di Banjarmasin jauh berada dibawah standar baku mutu yang ditetapkan sehingga harus dilakukan pengolahan terlebih dahulu.

Metode penjernihan air yang digunakan di PDAM Bandarmasin, yaitu dengan cara menambahkan koagulan kedalam air yang akan diolah dan diaduk secara merata yang biasa disebut proses koagulasi. Proses penambahan koagulan harus dilakukan secara efisien karena proses koagulasi ini merupakan proses yang menghabiskan biaya terbesar dari serangkaian proses pengolahan air yang ada di PDAM Bandarmasih. Jika dosis penambahan koagulan dilakukan secara berlebihan, akan menyebabkan biaya penggunaan bahan kimia koagulan menjadi membengkak sehingga membebani pengeluaran PDAM.

\section{METODE PENELITIAN}

Metode dalam penelitian ini yang akan digunakan yaitu dengan metode analitik dimana data dari hasil uji coba beberapa dosis koagulan Poli Aluminium Klorida (PAC) yang digunakan pada kegiatan jar test diteliti untuk dijadikan dasar dalam menentukan jumlah atau dosis koagulan Poli Aluminium Klorida (PAC) yang paling optimal.Untuk mengumpulkan data penelitian yang akan digunakan dalam penulisan tugas akhir ini, penulis menggunakan dua teknik metode penelitian, yaitu penelitian Library Research (Penelitian Kepustakaan) dan Field Research (Penelitian Lapangan).

\section{HASIL DAN PEMBAHASAN}




\section{Analisis Data}

Data yang digunakan untuk kegiatan analisis dalam tugas akhir ini didapat dari hasil pengujian di laboratorium dengan metode jar test, setelah itu dilakukan kegiatan observasi dan analisa data. Kegiatan observasi merupakan suatu proses penelitian dengan mengamati perubahan suatu kondisi dari bahan-bahan pengamatan yang dilakukan di laboratorium Perusahaan Daerah Air Minum (PDAM) Bandarmasih.

\section{A. Penambahan Kaustik Soda (NaOH)}

Penambahan kaustik soda $(\mathrm{NaOH})$ dilakukan untuk menaikkan $\mathrm{pH}$ air yang akan di olah menggunakan jar test dengan tujuan agar $\mathrm{pH}$ air mendekati kondisi $\mathrm{pH}$ optimum kerja koagulan PAC (Poly Aluminium Klorida) yaitu sekitar 7,1 - 7,5. Penambahan kaustik soda dilakukan sebelum proses penambahan kogulan PAC (Poly Aluminium Klorida). Tahapan proses penambahan kaustik soda $(\mathrm{NaOH})$ dilakukan sebagai berikut :

1. Sampel air yang akan di tambahkan kaustik soda $(\mathrm{NaOH})$ di letakkan ke dalam gelas kimia $500 \mathrm{ml}$ dan diukur nilai pH awalnya.

2. Masing- masing gelas kimia ditambahkan kaustik soda $(\mathrm{NaOH})$ sebanyak $8 \mathrm{mg}$ dan diaduk dengan kecepatan 140 rpm selama 1 menit agar tercampur.

3. Setelah itu dilakukan pengukuran $\mathrm{pH}$ air, setelah $\mathrm{pH}$ air berada di antara $\mathrm{pH} 7,1-7,5$ dapat dilanjutkan ke tahapan proses jar test.

\section{B. Uji Jar Test}

Sebelum melakukan pengujian jar test, terlebih dahulu dilakukan pengukuran parameter air yang akan diolah yaitu kekeruhan dan $\mathrm{pH}$ air. Selanjutnya dilakukan uji jar test terhadap sampel air mengikuti urutan sebagai berikut:

1. Sampel air yang akan diolah, dibagi kedalam 6 buah gelas kimia ukuran $1000 \mathrm{ml}$ atau biasa disebut dengan gelas jar test.

2. Masing-masing gelas jar test kemudian diberi koagulan $P A C$ (Poly Aluminium Klorida) dengan dosis yang berbeda-beda.

3. Setelah pembubuhan koagulan $P A C$ (Poly Aluminium Klorida), dilakukan pengadukan cepat dengan kecepatan pengadukan $140 \mathrm{rpm}$ selama 1 menit.

4. Setelah diaduk cepat selama 1 menit, pengadukan diperlambat sampai $40 \mathrm{rpm}$ selama 9 menit dengan maksud untuk meniru proses flokulasi. Setelah itu dihentikan untuk dilihat proses pengendapan.

5. Proses pengendapan dilakukan selama 20 menit.

6. Setelah prose pengendapan selama 20 menit, dilakukan pengukuran parameter kekeruhan dan $\mathrm{pH}$ air hasil jar test untuk mengetahui dosis penambahan koagulan PAC (Poly Aluminium Klorida) di gelas mana yang paling optimum.

Untuk dosis koagulan yang digunakan diperoleh dengan menghitung kadar koagulan PAC (Poly Aluminium Klorida) yang terkandung dalam pekatan larutan PAC (Poly Aluminium Klorida) dengan konsentrasi $12 \%$ yang dtambahkan pada proses jar test. Cara menghitung dosis koagulan dijabarkan sebagai berikut :

1. Gelas jar test 1 ditambahkan larutan PAC $12 \%$ sebanyak
$0.20 \mathrm{ml} / \mathrm{L}$ sehingga dosis PAC adalah :

$=1000 \mathrm{ml} \times 0,20 \mathrm{ml}$ larutan PAC $x 12 \%$ konsentrasi PAC

$=1000 \times 0,20 \times 0,12$

$=24 \mathrm{mg} /$ liter

2. Gelas jar test 2 ditambahkan larutan PAC $12 \%$ sebanyak $0.25 \mathrm{ml} / \mathrm{L}$ sehingga dosis $\mathrm{PAC}$ adalah :

$=1000 \mathrm{ml} \times 0,25 \mathrm{ml}$ larutan PAC $\times 12 \%$ konsentrasi PAC

$=1000 \times 0,25 \times 0,12$

$=30 \mathrm{mg} / \mathrm{hiter}$

3. Gelas jar test 3 ditambahkan larutan PAC $12 \%$ sebanyak $0.30 \mathrm{ml} / \mathrm{L}$ sehingga dosis PAC adalah :

$=1000 \mathrm{ml} \times 0,30 \mathrm{ml}$ larutan PAC $x 12 \%$ konsentrasi PAC $=1000 \times 0,30 \times 0,12$

$=36 \mathrm{mg} /$ hiter

4. Gelas jar test 4 ditambahkan larutan PAC $12 \%$ sebanyak $0.25 \mathrm{ml} / \mathrm{L}$ sehingga dosis PAC adalah :

$=1000 \mathrm{ml} \times 0,35 \mathrm{ml}$ larutan PAC $\times 12 \%$ konsentrasi PAC

$=1000 \times 0,35 \times 0,12$

$=42 \mathrm{mg} /$ liter

5. Gelas jar test 5 ditambahkan larutan PAC $12 \%$ sebanyak

$0.40 \mathrm{ml} / \mathrm{L}$ sehingga dosis $\mathrm{PAC}$ adalah :

$=1000 \mathrm{ml} \times 0,40 \mathrm{ml}$ larutan PAC $x 12 \%$ konsentrasi $P A C$

$=1000 \times 0,40 \times 0,12$

$=48 \mathrm{mg} /$ liter

6. Gelas jar test 6 ditambahkan larutan PAC $12 \%$ sebanyak $0.45 \mathrm{ml} / \mathrm{L}$ sehingga dosis PAC adalah :

$=1000 \mathrm{ml} \times 0,45 \mathrm{ml}$ larutan PAC $x 12 \%$ konsentrasi PAC

$=1000 \times 0,45 \times 0,12$

$=54 \mathrm{mg} /$ liter

\section{Hasil Uji Jar Test}

Pengujian jar test yang dilakukan di laboratorium PDAM Bandarmasih dilakukan dengan 2 metode berdasarkan bahan yang ditambahkan kedalam proses jar test. Metode pertama, jar test dilakukan dengan menambahkan koagulan PAC (Poly Aluminium Klorida) dengan dosis berbeda-beda antara $24-54 \mathrm{mg} / \mathrm{l}$. Metode kedua dengan menambahkan kaustik soda / soda ash terlebih dahulu kedalam air yang akan di olah setelah itu ditambahkan koagulan PAC (Poly Aluminium Klorida) dengan dosis antara $24-54 \mathrm{mg} / \mathrm{l}$. Yang membedakan 2 metode tersebut adalah adanya penambahan kaustik soda / soda ash terlebih dahulu sebelum penambahan koagulan. Untuk hasil pengujian jar test 2 metode tersebut adalah sebagai berikut.

\section{Hasil Uji Jar Test Metode 1}

Pengujian jar test metode 1 dilakukan sesuai dengan pengujian standar jar test, dimana air yang akan diolah, diukur parameter awalnya setelah itu ditambahkan koagulan PAC (Poly Aluminium Klorida) dengan dosis $24 \mathrm{mg} / \mathrm{l}, 30$ $\mathrm{mg} / \mathrm{l}, 36 \mathrm{mg} / \mathrm{l}, 42 \mathrm{mg} / \mathrm{l}, 48 \mathrm{mg} / \mathrm{l}$ dan $54 \mathrm{mg} / \mathrm{l}$. Setelah penambahan koagulan, dilakukan proses pengadukan cepat dengan kecepatan putaran $140 \mathrm{rpm}$ selama 1 menit 
dilanjutkan dengan pengadukan lambat dengan kecepatan 40 rpm selama 9 menit. Setelah proses pengadukan, dilanjutkan dengan proses pengendapan selama 20 menit. Setelah itu, air hasil jar test di uji untuk mengetahui kandungan parameter air yaitu kekeruhan dan $\mathrm{pH}$. Hasil uji jar test metode 1 ditampilkan pada Tabel 1 berikut :

Tabel 1 Hasil Pengujian Jar Test Metode 1

\begin{tabular}{|c|c|c|c|c|c|c|}
\hline \multicolumn{7}{|c|}{ TABEL HASIL PENGUJIAN JAR TEST } \\
\hline \multirow{2}{*}{$\begin{array}{c}\text { No } \\
\text { SAMPEL }\end{array}$} & \multicolumn{2}{|c|}{ PARAMETER AWAL } & \multirow{2}{*}{$\begin{array}{c}\text { DOSIS } \\
\text { KOAGULAN } \\
\text { PAC (mg/) } \\
\end{array}$} & \multicolumn{2}{|c|}{ PARAMETER HASIL JAR IEST } & \multirow{2}{*}{$\begin{array}{c}\text { EFSIENSI } \\
\text { KOAGULAN } \\
(\% \circ)\end{array}$} \\
\hline & \begin{tabular}{|c|} 
KEKERUHAN \\
(NIU)
\end{tabular} & $\mathrm{pH}$ & & $\begin{array}{l}\text { KEKERLHAN } \\
\text { (NTU) }\end{array}$ & $\mathrm{pH}$ & \\
\hline 1 & 19 & 6.5 & 24 & 3.28 & 6.3 & $83 \%$ \\
\hline 2 & 19 & 6.5 & 30 & 2.43 & 6.3 & $87 \%$ \\
\hline 3 & 19 & 6.5 & 36 & 1.88 & 0.3 & $90 \%$ \\
\hline 4 & 19 & 6.5 & 42 & 1.71 & 6.3 & $91 \%$ \\
\hline 5 & 19 & 6.5 & 48 & 1.44 & 6.3 & $92 \%$ \\
\hline 6 & 19 & 6.5 & 54 & 1.76 & 6.3 & $91 \%$ \\
\hline
\end{tabular}

Berdasarkan tabel 1, diketahui bahwa hasil pengukuran kekeruhan air hasil jar test berbeda-beda sesuai dengan dosis koagulan PAC (Poly Aluminium Klorida) yang ditambahkan.

\section{Hasil Uji Jar Test Metode 2}

Pada pengujian jar test metode 2 dilakukan penambahan kautik soda/soda ash sebanyak $8 \mathrm{mg} / \mathrm{l}$ terlebih dahulu kesetiap gelas jar test dan dilakukan pengadukan selama 3 menit agar kaustik soda/soda ash tercampur sempurna dengan air yang akan diolah. Setelah itu dilakukan uji jar test sesuai dengan pengujian standar, dimana air yang akan diolah, diukur parameter awalnya. Setelah itu ditambahkan koagulan PAC (Poly Aluminium Klorida) dengan dosis $24 \mathrm{mg} / \mathrm{l}, 30 \mathrm{mg} / \mathrm{l}, 36 \mathrm{mg} / \mathrm{l}, 42 \mathrm{mg} / \mathrm{l}, 48 \mathrm{mg} / \mathrm{l}$ dan $54 \mathrm{mg} / \mathrm{l}$. Setelah penambahan koagulan, dilakukan proses pengadukan cepat dengan kecepatan putaran $140 \mathrm{rpm}$ selama 1 menit dilanjutkan dengan pengadukan lambat dengan kecepatan 40 rpm selama 9 menit. Setelah proses pengadukan, dilanjutkan dengan proses pengendapan selama 20 menit. Setelah itu, air hasil jar test di uji untuk mengetahui kandungan parameter air yaitu kekeruhan dan $\mathrm{pH}$. Hasil uji jar test metode 1 ditampilkan pada tabel 2 berikut :

Tabel 2. Hasil Pengujian Jar Test Metode 2

\begin{tabular}{|c|c|c|c|c|c|c|c|}
\hline \multicolumn{8}{|c|}{ TABEL HASIL PENGUUAN JAR TEST DENGAN PENAMBAHAN KAUSTIK SODA/ SODAASH } \\
\hline \multirow{2}{*}{$\begin{array}{l}\text { NO } \\
\text { SAM PEL }\end{array}$} & \multirow{2}{*}{$\begin{array}{c}\text { DOSIS SODA } \\
\text { ASH (mg/) }\end{array}$} & \multicolumn{2}{|c|}{ PARAME TER AWAL } & \multirow{2}{*}{$\begin{array}{c}\begin{array}{c}\text { DOSIS } \\
\text { KOAGULAN } \\
\text { PAC (mgl) }\end{array} \\
\end{array}$} & \multicolumn{2}{|c|}{$\begin{array}{l}\text { PARAME TER HASIL JAR } \\
\text { TEST }\end{array}$} & \multirow{2}{*}{$\begin{array}{c}\begin{array}{c}\text { EFISIENSI } \\
\text { KOAGLAN } \\
(\%)\end{array} \\
\end{array}$} \\
\hline & & $\begin{array}{c}\text { KEKERUHAN } \\
\text { (NTU) }\end{array}$ & $\mathrm{pH}$ & & $\begin{array}{c}\text { KEKEERUHAN } \\
\text { (NTU) }\end{array}$ & $\mathrm{pH}$ & \\
\hline 1 & 8 & 19 & 7.4 & 24 & 2.87 & 7.3 & $85 \%$ \\
\hline 2 & 8 & 19 & 7.4 & 30 & 2.05 & 7.3 & $89 \%$ \\
\hline 3 & 8 & 19 & 7.4 & 36 & 1.63 & 7.3 & $91 \%$ \\
\hline 4 & 8 & 19 & 7.4 & 42 & 1.08 & 7.3 & $94 \%$ \\
\hline 5 & 8 & 19 & 7.4 & 48 & 0.88 & 7.3 & $95 \%$ \\
\hline 6 & 8 & 19 & 7.4 & 54 & 1.12 & 7.3 & $94 \%$ \\
\hline
\end{tabular}

\section{Hasil Penelitian}

Berdasarkan hasil pengujian jar test yang telah dilakukan. Diketahui jika tingkat kekeruhan air hasil jar test dipengaruhi oleh jumlah dosis koagulan PAC (Poly Aluminium Klorida) yang ditambahkan. Penambahan dosis koagulan yang paling optimum adalah penambahan dosis yang menghasilkan tingkat kekeruhan terendah atau nilai efisiesi pengolahan tertinggi. Berdasarkan hasil uji jar test dengan 2 buah metode yang telah dilakukan, diketahui bahwa dosis optimum penambahan koagulan PAC (Poly Aluminium Klorida) pada metode 1 adalah sebanyak $48 \mathrm{mg} / \mathrm{l}$ dengan tingkat kekeruhan hasil pengolahan sebesar 1.44 NTU. Untuk hasil uji jar test metode 2, diketahui bahwa dosis optimum penambahan koagulan PAC (Poly Aluminium Klorida) sebesar $48 \mathrm{mg} / \mathrm{l}$ dengan tingkat kekeruhan hasil pengolahan sebesar 0.88 NTU. Perbadingan hasil uji jar test metode 1 dan metode 2 dapat dilihat pada tabel 3 berikut :

Tabel 3. Perbandingan Hasil Uji Jar Test Metode dengan Metode 2

\begin{tabular}{|c|c|c|c|c|c|c|}
\hline \multicolumn{7}{|c|}{ PERBADINGAN HASIL UJI JAR TEST } \\
\hline \multirow{3}{*}{$\begin{array}{c}\text { No } \\
\text { SAMPEL }\end{array}$} & \multicolumn{6}{|c|}{ PARAMETER HASIL JAR TEST } \\
\hline & \multicolumn{3}{|c|}{ METODE 1} & \multicolumn{3}{|c|}{ METODE 2} \\
\hline & $\underset{\text { (NTU) }}{\text { KEKERUHAN }}$ & $\mathrm{pH}$ & $\begin{array}{c}\text { EFISIENSI } \\
\text { KOAGULAN (\%) }\end{array}$ & $\begin{array}{l}\text { KEKERUHAN } \\
\text { (NTU) }\end{array}$ & pH & $\begin{array}{c}\text { EFISIENSI } \\
\text { KOAGULAN (\%) }\end{array}$ \\
\hline 1 & 3.28 & 6.3 & $83 \%$ & 2.87 & 7.3 & $85 \%$ \\
\hline 2 & 2.43 & 6.3 & $87 \%$ & 2.05 & 7.3 & $89 \%$ \\
\hline 3 & 1.88 & 6.3 & $90 \%$ & 1.63 & 7.3 & $91 \%$ \\
\hline 4 & 1.71 & 6.3 & $91 \%$ & 1.08 & 7.3 & $94 \%$ \\
\hline 5 & 1.44 & 6.3 & $92 \%$ & 0.88 & 7.3 & $95 \%$ \\
\hline 6 & 1.76 & 6.3 & $91 \%$ & 1.12 & 7.3 & $94 \%$ \\
\hline
\end{tabular}

Berdasarkan tabel.3, terdapat perbedaan antara tingkat kekeruhan yang dihasilkan dari uji jar test metode 1 dan metode 2. Dimana dengan dosis penambahan koagulan yang sama, hasil uji jar test metode 2 menunjukkan hasil yang lebih baik jika dilihat dari nilai kekeruhan yang dihasilkan dari uji jar test metode 2 lebih kecil dari uji jart test metode 1 .

Berdasarkan tabel 4. terdapat perbedaan tingkat efisiensi pengolahan yang dihasilkan dari uji jar test metode 1 dan metode 2. Dari hasil uji jar test yang dilakukan, tingkat efisiensi yang dihasilkan dari metode 2 lebih besar dibandingkat metode 1 yang menggunakan dosis koagulan yang sama, metode 2 memiliki tingkat efisiensi tertinggi dengan nilai efisiensi pengolahan optimum sebesar 95\%. Hal ini disebakan karena adanya penambahan kaustik soda/soda ash yang menyebabkan $\mathrm{pH}$ air yang akan diolah naik menjadi 7,3 (tabel 4.3). Kenaikan $\mathrm{pH}$ air ini menyebabkan kinerja koagulan PAC (Poly Aluminium Klorida) menjadi lebih maksimal karena $\mathrm{pH}$ optimal untuk koagulan PAC (Poly Aluminium Klorida) berkisar antara 7,1 - 7,5 sehingga nilai efektifitas koagulan menjadi meningkat. Selain itu, jika melihat parameter kekeruhan yang dihasilkan jar test metode 2 dengan penambahan kaustik soda/soda ash menunjukkan nilai kekeruhan terkecil sebesar 0,88 NTU.

Berdasarkan hasil jar test yang telah dilakukan, terdapat perbedaan kondisi larutan hasil jar test berdasarkan jumlah dosis koagulan PAC (Poly Aluminium Klorida) yang ditambahkan dan metode jartest yang digunkana. Perbedaan kondisi larutan hasil jar test ditampilkan pada Tabel 4 dan 5 berikut ini : 
Tabel 4 Kondisi Larutan Hasil Jar Test Metode 1

\begin{tabular}{|c|c|c|l|}
\hline \multicolumn{5}{|c|}{ KONDISI LARUTAN HASIL JAR TEST METODE 1 } \\
\hline $\begin{array}{c}\text { No. } \\
\text { SAMPEL }\end{array}$ & $\begin{array}{c}\text { KEKERUHAN } \\
\text { (NTU) }\end{array}$ & $\begin{array}{c}\text { EFISIENSI } \\
\text { KOAGULAN } \\
(\%)\end{array}$ & \multicolumn{1}{|c|}{ KONDISI LARUTAN } \\
\hline 1 & 3.28 & $83 \%$ & $\begin{array}{l}\text { Larutan berwarna sedikit keruh dengan terdapat sedikit partikel pengotor } \\
\text { yang masih mengambang. Di bagian dasar gelas terdapat sedikit lapisan } \\
\text { endapan kotoran berwarna cokelat. }\end{array}$ \\
\hline 2 & 2.43 & $87 \%$ & $\begin{array}{l}\text { Larutan berwarna agak bening dengan terdapat sedikit partikel pengotor } \\
\text { yang masih mengambang. Di bagian dasar gelas terdapat endapan kotoran } \\
\text { berwarna cokelat dengan ketebalan sekitar 0.5 cm. }\end{array}$ \\
\hline 3 & 1.88 & $90 \%$ & $\begin{array}{l}\text { Larutan berwarna bening dan masih terlihat ada partikel pengotor yang } \\
\text { masih mengambang. Di bagian dasar gelas terdapat endapan kotoran } \\
\text { berwarna cokelat dengan ketebalan sekitar 1 cm. }\end{array}$ \\
\hline 5 & 1.71 & $91 \%$ & $\begin{array}{l}\text { Larutan berwarna bening dan masih terlihat ada partikel pengotor yang } \\
\text { masih mengambang. Di bagian dasar gelas terdapat endapan kotoran } \\
\text { berwarna cokelat dengan ketebalan sekitar 1 cm. }\end{array}$ \\
\hline 6 & 1.76 & $91 \%$ & $\begin{array}{l}\text { Larutan berwarna bening dan masih terlihat ada partikel pengotor yang } \\
\text { masih mengambang. Di bagian dasar gelas terdapat endapan kotoran } \\
\text { berwarna cokelat dengan ketebalan sekitar } 1 \mathrm{~cm} .\end{array}$ \\
\hline $\begin{array}{l}\text { barutan berwarna bening dan masih terlihat ada partikel pengotor yang } \\
\text { masih mengambang. Di bagian dasar gelas terdapat endapan kotoran } \\
\text { berwarna cokelat dengan ketebalan sekitar 1 cm. }\end{array}$ \\
\hline
\end{tabular}

Tabel 5 Kondisi Larutan Hasil Jar Test Metode 2

\begin{tabular}{|c|c|c|l|}
\hline \multicolumn{5}{|c|}{$\begin{array}{c}\text { KONDISI LARUTAN HASIL JAR TEST METODE 2 } \\
\text { No. } \\
\text { SAMPEL }\end{array}$} & $\begin{array}{c}\text { KEKERUHAN } \\
\text { (NTU) }\end{array}$ & $\begin{array}{c}\text { EFISIENSI } \\
\text { KOAGULAN } \\
(\%)\end{array}$ & \multicolumn{1}{|c|}{ KONDISI LARUTAN } \\
\hline 1 & 2.87 & $85 \%$ & $\begin{array}{l}\text { Larutan berwarna agak bening dengan terdapat sedikit partikel pengotor } \\
\text { yang masih mengambang. Di bagian dasar gelas terdapat endapan kotoran } \\
\text { berwarna cokelat dengan ketebalan sekitar } 0.5 \mathrm{~cm} .\end{array}$ \\
\hline 2 & 2.05 & $89 \%$ & $\begin{array}{l}\text { Larutan berwarna agak bening dengan terdapat sedikit partikel pengotor } \\
\text { yang masih mengambang. Di bagian dasar gelas terdapat endapan kotoran } \\
\text { berwarna cokelat dengan ketebalan sekitar } 0.5 \mathrm{~cm} .\end{array}$ \\
\hline 3 & 1.63 & $91 \%$ & $\begin{array}{l}\text { Larutan berwarna bening dan masih terlihat ada partikel pengotor yang } \\
\text { masih mengambang. Di bagian dasar gelas terdapat endapan kotoran } \\
\text { berwarna cokelat dengan ketebalan sekitar } 1 \mathrm{~cm} .\end{array}$ \\
\hline 5 & 1.08 & $94 \%$ & $\begin{array}{l}\text { Larutan berwarna bening dan masih terlihat ada partikel pengotor yang } \\
\text { masih mengambang. Di bagian dasar gelas terdapat endapan kotoran } \\
\text { berwarna cokelat dengan ketebalan sekitar } 1 \mathrm{~cm} .\end{array}$ \\
\hline 6 & 1.12 & $94 \%$ & $\begin{array}{l}\text { Larutan berwarna bening, partikel pengotor yang masih mengambang } \\
\text { sudah tidak terlihat. Di bagian dasar gelas terdapat lapisan tebal endapan } \\
\text { kotoran berwarna cokelat. }\end{array}$ \\
\hline
\end{tabular}

\section{KESIMPULAN}

Berdarkan hasil uji jar test di laboratorium PDAM Bandarmasih kota Banjarmasin, didapatkan hasil penelitian sebagai berikut :

1. Dosis optimum koagulan PAC (Poly Aluminium Klorida) untuk pengolahan air bersih di PDAM Bandarmasih sebesar $48 \mathrm{mg} / \mathrm{l}$ dengan paramater kekeruhan hasil jar test sebesar 1,44 NTU untuk metode jar test 1 dan 0,88 NTU untuk metode jar test 2.

2. Penambahan kaustik soda / soda ash berpengaruh terhadap peningkatan hasil uji jar test untuk tingkat kekeruhan dan efisiensi pengolahan. Dimana dengan menambahkan kaustik soda / soda ash, nilai parameter kekeruhan menjadi lebih kecil (0,88 NTU) dan nilai efisiensi pengolahan menjadi lebih besar (95\%). Peningkatan hasil uji jar test disebabkan karena adanya peningkatan $\mathrm{pH}$ air yang akan di olah menjadi 7,3 dimana kondisi $\mathrm{pH}$ air tesebut masuk kedalam kondisi $\mathrm{pH}$ optimal kinerja koagulan PAC (Poly Aluminium Klorida) yang berada di kisaran $\mathrm{pH} 7,1$ sampai dengan 7,5. 


\section{DAFTAR PUSTAKA}

[1] Anonim. 2010. Peraturan Pemerintah Menteri Kesehatan No. 492 Tahun 2010 tentang Persyaratan Kualitas iar Minum.

[2] Al-Layla, M.Anis et.al.1978. Water Suplay Engineering Design. Ann Arbor Science Publishers Inc. Michigan. USA.

[3] Darmasetiawan, Martin. 2001. Teori dan Perencanaan Instalasi Pengolahan Air. Bandung : Yayasan Suryono.

[4] Ignasius D.A. Sutapa. 2014. Optimalisasi Dosis Koagulan Aluminium Sulfat Dan Poli-Aluminium Klorida (Pac) Untuk Pengolahan Air Sungai Tanjung Dan Krueng Raya. Jurnal.

[5] Kawamura. S. 1991. Integrated Design of Water Treatment Facilities. New York : John Wiley and Sons. Inc.

[6] Kirk-Othmer Encyclopedia of Chemical Technology 5th edition (online, account needed),

[7] John Wiley \& Sons. Accessed November 21, 2005.

[8] M.A. Al-Layla. 1980. Water Supply Engineering Design. 2nd Edition. Michigan, USA : Ann Arbor Science Publishers. Inc.

[9] Muhammad haykal nur ramadhansyah. 2017. Perbandingan Kebutuhan Koagulan $\mathrm{Al}_{2}\left(\mathrm{SO}_{4}\right)_{3}$ Dan Pac Untuk Pengolahan Air Bersih Di Water Treatment Plant Pdam Kota Bandung. Jurnal
[10] Notoatmodjo, S. 2007. Kesehatan Masyarakat Ilmu dan Seni. Jakarta : Rineka Cipta.

[11] Peavy, Howard S et.al. 1985. Environmental Engineering. McGrawHill. Singapura.

[12] Rizka Mayasari dan Merisha Hastarina. 2018. Optimalisasi Dosis Koagulan Aluminium Sulfat Dan Poli Aluminium Klorida (Pac) (Studi Kasus Pdam Tirta Musi Palembang). Jurnal. L

[13] Riyadil Afdal, Fadhilah. 2017. Optimasi Penggunaan Koagulan Pc300 Dan flokulan A100 Untuk Proses Pengolahan Air Limbah Tambang Di Wwtp01 Pt. Mitrabara Adiperdana,Tbk.Jurnal.

[14] Septyn Anggun Lestari. 2018. Efektivitas Penggunaan Bahan Koagulan Dalam Proses Perencanaan Pengolahan Bangunan Air Minum. Jurnal

[15] Schroeder, E.D. 1977.Water and Wastewater Treatment. New York.

[16] Sutrisno. 2004. Teknologi Penyediaan Air Bersih. Jakarta: PT Rineka Cipta

[17] Wityasari, Nurani.2015. Penentuan Dosis Optimum Pac (Poly Aluminium Chloride) Pada Pengolahan Air Bersih Di Ipa Tegal Besar Pdam Jember. Jurnal.

[18] Wibisono, M.S. 2005. Pengantar Ilmu Kelautan. PT Grasindo anggota IKAPI. Jakarta. 